\title{
Community Attitudes Towards Violence Against Women, and Lived Experiences of Family Violence and Abuse During Childhood in Rural Eastern Nigeria: Implications for Policy and Programming
}

\author{
ljeoma Nkem Okedo-Alex (iD) ${ }^{1,2}$ \\ Ifeyinwa Chizoba Akamike ${ }^{1,2}$ \\ Chigozie Jesse Uneke (D) \\ Dejene Derseh Abateneh iD $^{3}$ \\ 'African Institute for Health Policy and \\ Health Systems, Ebonyi State University, \\ Abakaliki, Ebonyi State, Nigeria; \\ ${ }^{2}$ Department of Community Medicine, \\ Alex Ekwueme Federal University \\ Teaching Hospital, Abakaliki, Ebonyi \\ State, Nigeria; ${ }^{3}$ Department of Medical \\ Laboratory Sciences, Menelik II College \\ of Medicine and Health Sciences, Kotebe \\ Metropolitan University, Addis Ababa, \\ Ethiopia
}

Correspondence: Dejene Derseh Abateneh

Kotebe Metropolitan University, Menelik

II College of Medicine and Health

Sciences, Department of Medical

Laboratory Sciences, P.O. Box: 3268,

Addis Ababa, Ethiopia

Tel +2519205।4158

Email dejenieh@gmail.com

ljeoma Nkem Okedo-Alex

African Institute for Health Policy and

Health Systems, Ebonyi State University

(EBSU), Abakaliki, Nigeria

Email ijeomaninadr@gmail.com
Background: Violence against women (VAW) has remained an increasingly significant public health problem globally. This study explored childhood experiences of abuse and attitude towards violence against women among adults in a rural community in South-east Nigeria.

Methods: This was a cross-sectional study conducted in a rural community in Ebonyi, Nigeria. Data were collected from 280 respondents using interviewer-administered questionnaires. Data analysis was performed using SPSS version 25.

Results: The mean age of the male participants was $46.5 \pm 16.8$, while that for the female participants was $43.3 \pm 16.9$. Most were females $(203 / 280,72.5 \%)$, out of which $(83 / 203$, $40.9 \%$ ) had secondary school as the highest level of education attained. Most participants were females (203/280, 72.5\%), married (225/280, 80.4\%) with secondary school education (124/280, $44.3 \%)$. More than one-tenth $(33 / 280,11.8 \%)$ had ever witnessed parental violence, while $46.4 \%$ had been physically abused in childhood. Forced touching and penetrative sex was experienced sometimes by $11.4 \%$ (32/280) and $21.8 \%(61 / 289)$, respectively. Overall, the majority $(258 / 280$, $92.8 \%$ ) had a disapproving attitude towards gender-based violence. Most participants disagreed that hitting or insulting woman was not wrong $(246 / 280,87.9 \%)$. The majority of the respondents agreed that women were inferior to men from a cultural perspective (175/280, 62.5\%). Almost half strongly agreed $(125 / 2280,44.6 \%)$ and agreed $(118 / 280,42.1 \%)$ that a woman is a man's possession. The predictors of attitude were secondary school education ( $\mathrm{AOR}=7.74,95 \% \mathrm{CI}=$ 1.69-35.54) and monogamous marital setting ( $\mathrm{AOR}=2.83,95 \% \mathrm{CI}=1.08-7.42$ ).

Conclusion: This study showed that Nigerian adults had high levels of childhood exposures to family violence, physical and sexual abuse. Overall, the majority disapproved of VAW; however, there were gaps that endorsed patriarchal ideologies. Interventions to address VAW should include components targeted at children exposed to violence and de-bunking patriarchal ideologies that encourage VAW.

Keywords: domestic violence, gender-based violence, intimate partner violence, family violence, childhood, rural Nigeria

\section{Introduction}

Violence against Women (VAW) has remained an increasingly significant public health problem globally. It violates the rights of women and adversely affects their physical, mental, sexual, and reproductive health. ${ }^{1,2}$ Women who are victims of VAW are predisposed to low birth weight babies, sexually transmitted infections, depression, alcohol use disorders, injuries and death from murder. ${ }^{3}$ They also face enormous barriers in access to 
quality health and non-health services and this is further compounded by stigma, harmful cultural beliefs/practices and poor socioeconomic status. ${ }^{4}$ Beyond the health effects, the presence of VAW is inimical to the attainment of sustainable growth and development and further perpetuates inequity. ${ }^{5}$

The United Nations defines Violence against women as "any act of gender-based violence that results in, or is likely to result in, physical, sexual, or mental harm or suffering to women, including threats of such acts, coercion or arbitrary deprivation of liberty, whether occurring in public or in private life". 5 In a lifetime, $35 \%$ of women are likely to face physical and/or sexual abused by an intimate or non-intimate partner. ${ }^{1,6}$ Using World Health Organization (WHO) regions, the prevalence of intimate partner violence is highest in the South-east Asian, Eastern Mediterranean and African regions. ${ }^{6}$ In Nigeria, 33\% of women in the reproductive age group (15-49 years) have been victims of sexual or physical violence. ${ }^{7}$ The prevalence of physical violence by an intimate partner since they were aged 15 years has steadily increased from $28 \%$ in 2008 to $31 \%$ in $2018 .^{7}$

Violence against women has both direct and indirect dire consequences for the other local vulnerable actors such as children. ${ }^{1}$ Children who experience abuse are more likely to become perpetrators and/or victims of (Gender-based Violence) GBV in adulthood. This is also applicable to those who are exposed to intimate partner violence between parents, caregivers and other local adult influencers. ${ }^{8-13}$ In the short-term, they are prone to psychological trauma, low self-esteem, physical issues and even death. ${ }^{8,14,15}$ Thus, there has been a growing emphasis on understanding and preventing childhood abuse and/or exposure to Intimate Partner Violence (IPV). Childhood is also a critical period of socialization that could result in endorsement of gender-inequitable norms and the adoption of stereotypes that predispose to VAW. ${ }^{16}$

Community gender norms and attitudes towards violence against women are important in understanding the experience, perpetration and perpetuation of gender-based violence. $^{2}$ Poor knowledge, low status of women patriarchy and harmful traditional practices influence the prevalence and under-reporting of VAW. ${ }^{17-19}$ Africa (Nigeria inclusive) largely exists as a patriarchal society with limited autonomy and access to resources by women. ${ }^{20-22}$ Also both men and women have been shown to have favour VAW despite being perpetrators, victims and survivors. $^{17,18,23,24}$ According to the 2018 Nigerian national demographic and health survey (NDHS), one in three Nigerian women in the reproductive age category have experienced physical violence while $9 \%$ have been victims of sexual violence. ${ }^{7}$ The prevalence of spousal violence in 2018 was higher compared to levels in the NDHS of 2013 and 2008. ${ }^{7}$ The Nigerian law on Violence Against Persons Prohibition (VAPP) passed at a national level in 2015 covers issues of domestic violence, various forms of sexual abuse and related crimes but has only been adopted (passed into law at sub-national level) by about seven States in Nigeria. ${ }^{25}$ The aim of this study was to explore childhood experiences of abuse and attitude towards violence against women among adults in a rural community in South-east Nigeria.

\section{Methods \\ Study Area}

This study was conducted in a rural community of Onicha Local Government Area (LGA) in Ebonyi State. Ebonyi is one of the five States in South east Nigeria and is majorly occupied by the Ibos with $>70 \%$ of them residing in the rural areas and engaged in Agriculture. The State has thirteen Local Government Areas (LGAs). This study was conducted in Ebonyi State because it has the highest prevalence of physical (54.7\%) and spousal violence $(20.8 \%)$ out of the five States in South-east Nigeria ${ }^{7}$ and the State's VAPP law was passed in 2018.

\section{Study Participants}

The study population were men and women aged at least 18 years of old who were sexually active. Adults who have never been in an intimate relationship and those who declined to consent to the study were excluded from the study.

\section{Study Design}

A cross-sectional study design was employed.

\section{Sample Size Determination and Sampling}

Data was collected from all eligible respondents (203 women and 77 men) who participated in a community sensitization exercise. The community sensitization was held as part of the activities for a project on prevention of malaria in pregnancy in the community. The community members were all given an open invitation to attend the sensitization. The information on the sensitization event such as the date, venue, time and purpose of the meeting were conveyed through town criers (multiple 
announcements), announcements during community social group meetings and mobilization by the community leaders.

\section{Data Collection Methods}

Information for the study was collected using a pre-tested semi-structured interviewer-administered questionnaire adapted from previous demographic surveys. ${ }^{7,26,27}$

The questionnaire was divided into three sections. The first section of the questionnaire collected information on socio-demographic profile of the respondents, the second explored childhood experiences of family violence while the third section assessed attitude towards violence against women. Childhood experiences of abuse was assessed using four questions on exposure to family or domestic violence involving parents/caregivers (Yes/No options), physical abuse, forced penetrative and non-penetrative (touching) sexual abuse (5-point Likert-scale questions measured on a scale of Never, Rarely, Sometimes, Often, Always).

Attitude towards VAW was explored using nine questions on measured on a 5-point Likert scale of agreement. Six of the questions were negatively constructed and scored as follows: 1 point $=$ strongly agree; 2 points $=$ agree; 3 points $=$ neutral; 4 points $=$ disagree and 5 points $=$ strongly disagree. The remaining three questions were scored with strongly agree having the highest score of five points while strongly disagree was scored as one point. Overall attitude was graded using the Mean Neutral Rating (MNR) of the Likert scale responses using the methods developed at McMaster University Canada by Johnson and Lavis. ${ }^{28}$ This was calculated per Likert question using the score assigned to each Likert response to calculate the mean of the overall responses of the various participants to that question. Mean attitudes between 3.00 and 5.00 were categorized as disapproving (good) while mean attitudes less than 3.00 were classified as approving (poor). Data were collected separately for each participant by five trained graduate research assistants.

\section{Data Analysis}

The socio-demographic characteristics of the respondents were the independent variables while childhood experiences of abuse and attitudes towards violence against women.

Statistical analysis was performed using IBM-SPSS version 25 software. $^{29}$ Descriptive statistics were summarized as means and standard deviations for numerical variables and proportions for qualitative variables. The Chi-square test was used to determine the relationship between the independent variables and attitude towards VAW. The variables with $\mathrm{p}$ value $<0.2$ following bivariate analysis were included in the logistic regression model.

\section{Ethics Approval and Informed Consent}

This study was conducted in accordance with the Declaration of Helsinki and after ethical clearance was obtained from the research and ethics committee of Ebonyi State Ministry of Health. Only participants who participated voluntarily and provided written informed consent were included in the study. Confidentiality, privacy and anonymity of the responses received were ensured. To ensure confidentiality, the questionnaire did not contain any self-identifying information. Data was stored in a password-enabled computer that was only accessible to the primary researcher.

\section{Results}

The mean age of the male participants was $46.5 \pm 16.8$ while that for the female participants was $43.3 \pm 16.9$. Most were females (203/280, 72.5\%), out of which (112/ $203,55.2 \%$ ) were married in a monogamous setting and $(83 / 203,40.9 \%)$ had secondary school as the highest level of education attained [Table 1].

More than one-tenth $(33 / 280,11.8 \%)$ had ever witnessed parental violence, physical, sexual or other forms of violence as a child. Almost half (130/280, 46.4\%) had been physically abused in childhood at a mean age of 9.88 \pm 4.3 at first abuse. Forced touching and penetrative sex was experienced sometimes by $11.4 \%$ (32/280) and $21.8 \%$ (61/289), respectively [Table 2].

Most participants disagreed that hitting or insulting woman was not wrong $(246 / 280,87.9 \%)$. The majority of the respondents agreed that women were inferior to men from a cultural perspective $(175 / 280,62.5 \%)$. Over $60 \%(172 / 280,61.4 \%)$ strongly agreed that perpetrators of IPV should be prosecuted and brought to justice. Almost half strongly agreed (125/2280, 44.6\%) and agreed (118/ $280,42.1 \%$ ) that a woman is a man's possession [Table 3].

Participants who had at least a secondary school education were 7.74 times more likely to have a disapproving attitude towards GBV $(\mathrm{AOR}=7.74,95 \% \mathrm{CI}=1.69-$ 35.54). Married participants who were in a monogamous setting had 2.83 times higher odds of having 
Table I Socio-Demographic Characteristics of the Respondents

\begin{tabular}{|c|c|c|}
\hline Variables & Males (\%) & Females (\%) \\
\hline Mean Age (years $\pm S D)$ & $46.5 \pm 16.8$ & $43.3 \pm 16.9$ \\
\hline Median Age [IQR] & $44[34.5-57.0]$ & $39.0[30.0-55.0]$ \\
\hline \multicolumn{3}{|l|}{ Age group (years) } \\
\hline $15-25$ & $5(6.5)$ & $21(10.3)$ \\
\hline $26-35$ & $19(24.7)$ & $62(30.5)$ \\
\hline $36-45$ & $17(22.1)$ & $43(21.2)$ \\
\hline$>45$ & $36(46.8)$ & $77(37.9)$ \\
\hline \multicolumn{3}{|l|}{ Educational level } \\
\hline None & $7(9.1)$ & $52(25.6)$ \\
\hline Primary & $27(35.1)$ & $65(32.0)$ \\
\hline Secondary & $42(54.5)$ & $82(40.4)$ \\
\hline Tertiary & $\mathrm{I}(\mathrm{I} .3)$ & $4(2.0)$ \\
\hline \multicolumn{3}{|l|}{ Partner's education } \\
\hline None & $10(13.0)$ & $46(22.7)$ \\
\hline Primary & $27(35.1)$ & $69(34.0)$ \\
\hline Secondary & $40(51.9)$ & $83(40.9)$ \\
\hline Tertiary & $0(0.0)$ & $5(2.5)$ \\
\hline \multicolumn{3}{|l|}{ Relationship status } \\
\hline Single in committed relationship & $6(7.8)$ & $2(1.0)$ \\
\hline Single in casual relationship & $1(1.3)$ & $3(1.5)$ \\
\hline Married & $67(87.0)$ & $158(77.8)$ \\
\hline Divorced & $0(0.0)$ & $4(2.0)$ \\
\hline Widowed & $3(3.9)$ & $36(17.7)$ \\
\hline \multicolumn{3}{|l|}{$\begin{array}{l}\text { Decision-maker on major life } \\
\text { issues }\end{array}$} \\
\hline Me alone & $12(15.6)$ & $27(13.3)$ \\
\hline Joint with partner & $62(80.5)$ & $169(83.3)$ \\
\hline Partner alone & $3(3.9)$ & $7(3.4)$ \\
\hline \multicolumn{3}{|l|}{ Marital status and type } \\
\hline Currently unmarried & $7(9.1)$ & $5(2.5)$ \\
\hline Monogamy & $50(64.9)$ & $112(55.2)$ \\
\hline Polygamy & $20(26.0)$ & $86(42.4)$ \\
\hline \multirow{2}{*}{\multicolumn{3}{|c|}{$\begin{array}{l}\text { Duration (years) in marriage } \\
(\mathrm{n}=268)\end{array}$}} \\
\hline & & \\
\hline $1-5$ & $17(22.1)$ & $38(19.7)$ \\
\hline $6-10$ & $13(16.9)$ & $35(17.2)$ \\
\hline$>10$ & $40(51.9)$ & $125(61.6)$ \\
\hline \multicolumn{3}{|l|}{ Religion } \\
\hline Christianity & $61(79.2)$ & $202(99.5)$ \\
\hline Traditional & $16(20.8)$ & $\mathrm{I}(0.5)$ \\
\hline \multicolumn{3}{|l|}{ Occupation } \\
\hline Farmer & $34(44.2)$ & $104(51.2)$ \\
\hline Civil servant & $8(10.4)$ & $15(7.4)$ \\
\hline Self-employed & $13(16.9)$ & $18(8.9)$ \\
\hline Artisan & $6(7.8)$ & $5(2.5)$ \\
\hline Trader & $13(16.9)$ & $57(28.1)$ \\
\hline Student & $0(0.0)$ & $3(1.5)$ \\
\hline Not working & I (I.3) & I (0.5) \\
\hline Others & $2(2.6)$ & $0(0.0)$ \\
\hline \multicolumn{3}{|l|}{ No of living children } \\
\hline None & $5(6.5)$ & $16(7.9)$ \\
\hline $1-3$ & $21(27.3)$ & $67(33.0)$ \\
\hline $4-6$ & $16(20.8)$ & 77 (37.9) \\
\hline$>6$ & $35(45.5)$ & $43(21.2)$ \\
\hline
\end{tabular}

Table 2 Childhood Witnessing and Experiences of Sexual and Non-Sexual Abuse

\begin{tabular}{|c|c|c|}
\hline Variable & Frequency & $\begin{array}{l}\text { Percentage } \\
\text { (\%) }\end{array}$ \\
\hline \multirow{3}{*}{\multicolumn{3}{|c|}{$\begin{array}{l}\text { Ever witnessed parental } \\
\text { physical, sexual or other forms } \\
\text { of violence as a child }\end{array}$}} \\
\hline & & \\
\hline & & \\
\hline No & 223 & 79.6 \\
\hline Yes & 33 & 11.8 \\
\hline Do not know & 24 & 8.6 \\
\hline \multirow{2}{*}{\multicolumn{3}{|c|}{$\begin{array}{l}\text { If yes how many times (assuming } \\
\text { a } 3 \text {-month period) } n=33\end{array}$}} \\
\hline & & \\
\hline Rarely (once in 3 months) & 12 & 4.3 \\
\hline Sometimes (monthly) & 18 & 6.4 \\
\hline Often ( 4 times in 3 months) & 2 & 0.7 \\
\hline $\begin{array}{l}\text { Always ( } 5 \text { or more times in } 3 \\
\text { months) }\end{array}$ & 1 & 0.4 \\
\hline \multicolumn{3}{|l|}{$\begin{array}{l}\text { Ever physically abused in } \\
\text { childhood }\end{array}$} \\
\hline No & 150 & 53.6 \\
\hline Yes & 130 & 46.4 \\
\hline $\begin{array}{l}\text { Mean age of first physical abuse } \\
\text { (years } \pm S D)[n=130]\end{array}$ & $9.88 \pm 4.3$ & \\
\hline \multicolumn{3}{|l|}{$\begin{array}{l}\text { Forced non-penetrative sexual } \\
\text { abuse (touching) in childhood }\end{array}$} \\
\hline Never & 241 & 86.1 \\
\hline Rarely & 7 & 2.5 \\
\hline Sometimes & 32 & 11.4 \\
\hline Often & 0 & 0.0 \\
\hline Always & 0 & 0.0 \\
\hline \multicolumn{3}{|l|}{$\begin{array}{l}\text { Forced penetrative sexual abuse } \\
\text { in childhood }\end{array}$} \\
\hline Never & 209 & 74.6 \\
\hline Rarely & 10 & 3.6 \\
\hline Sometimes & 61 & 21.8 \\
\hline Often & 0 & 0.0 \\
\hline Always & 0 & 0.0 \\
\hline
\end{tabular}

a disapproving attitude towards GBV (AOR $=2.83,95 \%$ $\mathrm{CI}=1.08-7.42)$ [Table 4].

The majority $(258 / 280,92.8 \%)$ had a disapproving attitude towards gender-based violence.

\section{Discussion}

This study assessed childhood experiences of abuse and attitude towards violence against women among rural residents in South-east Nigeria.

This study found that 1 in 10 respondents had observed the physical, sexual or other forms of the abuse of a parent during childhood. Spousal violence has been on a steady 
Table 3 Attitude Towards Intimate Partner Violence Among the Respondents

\begin{tabular}{|c|c|c|c|c|c|}
\hline Variable & $\begin{array}{l}\text { Strongly } \\
\text { Disagree }\end{array}$ & Disagree & Undecided & Agree & $\begin{array}{l}\text { Strongly } \\
\text { Agree }\end{array}$ \\
\hline A woman is supposed to only speak when authorized by a man & $79(28.2)$ & $110(39.3)$ & $3(1.1)$ & $52(18.6)$ & $36(12.9)$ \\
\hline A man hitting or insulting a woman (or other forms of abuse) is not wrong & $138(49.3)$ & $108(38.6)$ & $\mathrm{I}(0.4)$ & $16(5.7)$ & $17(6.1)$ \\
\hline In the participant's culture, a woman is inferior to a man & $43(15.4)$ & $57(20.4)$ & $5(1.8)$ & $139(49.6)$ & $36(12.9)$ \\
\hline A man that beats his woman is man enough & $124(44.3)$ & $126(45.0)$ & $\mathrm{I}(0.4)$ & $12(4.3)$ & $17(6.1)$ \\
\hline A woman should not be involved in major decision-making in the relationship & $108(38.6)$ & $126(45.0)$ & I (0.4) & $23(8.2)$ & $22(7.9)$ \\
\hline Victims of IPV should be provided with special care and support & $17(6.1)$ & $6(2.1)$ & $3(1.1)$ & $164(58.6)$ & $90(32.1)$ \\
\hline A woman is a man's possession (especially in marriage settings & $16(5.7)$ & $18(6.4)$ & $3(1.1)$ & $118(42.1)$ & $125(44.6)$ \\
\hline A perpetrator of IPV should be prosecuted and brought to justice & $9(3.2)$ & $5(1.8)$ & $2(0.7)$ & $92(32.9)$ & $172(61.4)$ \\
\hline Communities should enact legislation against IPV and prosecute offenders & $4(1.4)$ & $4(1.4)$ & $2(0.7)$ & $108(38.6)$ & $162(57.9)$ \\
\hline
\end{tabular}

Table 4 Predictors of Attitude Towards Gender-Based Violence

\begin{tabular}{|c|c|c|c|c|}
\hline \multirow{2}{*}{ Independent Variable } & \multirow{2}{*}{$\begin{array}{l}\text { Adjusted } \\
\text { Odds Ratio }\end{array}$} & \multicolumn{2}{|c|}{ 95\% Cl for AOR } & \multirow[t]{2}{*}{$P$ value } \\
\hline & & Lower & Upper & \\
\hline \multicolumn{5}{|l|}{ Age (years) } \\
\hline$\leq 45$ & 1.28 & 0.48 & 3.38 & 0.619 \\
\hline$>45$ & I & & & \\
\hline \multicolumn{5}{|l|}{ Educational status } \\
\hline Primary and less & I & & & \\
\hline Secondary and more & 7.74 & 1.69 & 35.54 & $0.009 *$ \\
\hline \multicolumn{5}{|l|}{ Marital setting } \\
\hline Monogamy & 2.83 & 1.08 & 7.42 & $0.035^{*}$ \\
\hline Polygamy & I & & & \\
\hline
\end{tabular}

Note: *Significantly associated.

rise in Nigeria with $36 \%$ of women in-union experiencing physical, sexual, or emotional violence in $2018 .^{7}$ This is higher than levels recorded in 2008 and 2013 and has been further worsened by the COVID-19 pandemic. ${ }^{4}$ Childhood observation of parental abuse has been associated with both victimization and perpetration of VAW as well as violence-acceptance and negative mental health effects. ${ }^{9,30,31}$ This is because abuse and violence follows an intergenerational vicious cycle pattern due to the rationalization and violence-accepting stereotypes formed by exposure to family violence. ${ }^{32}$ Therefore, VAW requires an integrated approach aimed at preventing abuse as well as providing psychological and other forms of care to people (especially children) who have witnessed abuse.

Almost half of the respondents in this study had been physically abused in childhood. Spates of public violence and civil unrests have been a recurrence in the Nigerian context (notably the Fulani herdsmen attacks, and Indigenous People of Biafra (IPOB revolutions in Southeast Nigeria including Ebonyi State)) and this could lead to the normalization of physical violence as a way of getting things done. Exposure to family violence has been found to be remarkably high among Nigerians. $^{11}$ Also, physical discipline is a wellestablished part of child rearing in Nigerian societies and may have been misconstrued as physical abuse by the respondents. Thus, the contextually blurred lines between physical discipline and abuse could have contributed to the findings. In another study among university students in Southwest Nigeria, 28.2\% reported being physically abused before the age of $15 .^{30}$ A nationally representative data found that $31 \%$ of Nigerian women aged 15-49 years had ever experienced physical abuse since 15 years of age. ${ }^{7}$ The higher prevalence in our study could be because we assessed the prevalence in both men and women regardless of the age at which the experience occurred. Given the unintended consequences of childhood exposure to violence viz tolerance towards violence and/or predisposition to violence in adulthood, ${ }^{33}$ non-physical options for child discipline or dispute resolution should be explored by caregivers and parents. 
During childhood, $13.9 \%$ of the respondents had been forcefully touched sexually while one in four of them had experienced penetrative sexual abuse. In contrast, only $9.6 \%$ of young adults had ever been touched in a sexual way in another study in Oyo, Nigeria. ${ }^{30}$ The use of an age cut-off of 15 years, and recall bias resulting in under- or over-reporting may account for the differences in prevalence. A similar study among American adults found that $16.7-26.7 \%$ of adults had been sexually abused in childhood. ${ }^{9}$ The higher prevalence in that study could be due to the use of multiple questions to explore sexual abuse and self-administration of the questions possibly resulting in higher levels of disclosure. However, this prevalence combined experiences of penetrative and nonpenetrative child sexual abuse and explored experiences below 14 years of age. The prevalence of non-consented sexual penetration was twice that of sexual touching. This could be because it may be easier for the child to flee away from being touched as against penetration. Also, perpetrators may be more likely to gain sexual satisfaction through penetrative sex. They may also derive pleasure in the struggles of the victim (seen as a sign of sexual domination and love expression) before being overpowered. ${ }^{34}$

Overall, the majority of the respondents disapproved of VAW. Such favourable disposition towards VAW has been reported in other studies. Similar to other studies, participants supported the involvement of women in family decision-making. ${ }^{30}$ It is also worthy of note that participants supported the prosecution of perpetrators. This could signal the potentially glowing embers of change which need to be fanned into a raging fire of justice especially as VAW remains under-reported and prosecuted in the Nigerian context. Public punitive measures against perpetrators has been described as weak and incapable of deterring intending perpetrators or encouraging reporting by victims. ${ }^{11}$ It is therefore important to adopt a whole-of-system approach in curbing the burgeoning pandemic of VAW, especially given the recent exacerbations during the COVID-19 pandemic. $^{4}$

Despite the disapproval of VAW, this study found it disturbing that most respondents did not disapprove of wife beating, and women's inferiority to men. Additionally, most considered women to be the possession of men. This notion is adopted typically after the payment of the bride price (dowry) which culturally signifies the acquisition cum transfer of ownership rights from the parents to the husband. ${ }^{11}$ Thus, this attitude is rooted in the cultural milieu fueling the patriarchal nature of African societies with the attendant subordination of women. ${ }^{35,36}$ Patriarchy results in gender inequity and power imbalance and is especially prevalent in rural communities such as the study context. Additionally, studies have found that young Nigerians were prone to endorsing negative beliefs about VAW because of their exposure to gendered socio-cultural and religious norms. ${ }^{11}$ It is therefore exigent that community efforts to address patriarchy, improve the autonomy and status of women be intensified or kick-started where non-existent.

Being married in a monogamous setting increased the odds of disapproval towards VAW. Generally, polygamy may be associated co-wife rivalry, unmet socio-economic needs, absence of shared decision-making and autonomy, all of which set the stage for VAW and an attitude of approval towards it. The converse may obtain in monogamous settings where there is more individualism, and less competition thereby resulting in an anti-VAW disposition. Respondents who were educated to at least the secondary school level demonstrated more disapproval towards VAW. Access to higher levels of formal education could provide the exposure to information required to debunk patriarchal ideologies thus resulting in an approving attitude towards VAW.

This is one of the few studies to contribute to the knowledge base on childhood exposures to abuse and attitudes towards violence against women. The study findings could have been biased due to recall and selfreporting limitations; however, the respondents were encouraged to give sincere responses having been assured of confidentiality and anonymity. The authors acknowledge that the limitation of not exploring participant's access to the internet or other information sources on VAW. Also, the conduct of this study in one rural community as well as the possible non-representativeness of the study participants limits the generalizability of the study findings.

\section{Conclusion}

This study showed that Nigerian adults had high levels of childhood exposures to family violence, physical and sexual abuse. Overall, the majority had an attitude of disapproval towards VAW; however, gaps existed in beliefs regarding possessive disposition of men over women, cultural inferiority of women, physical and verbal violence towards women. Interventions to address VAW should include components targeted at children exposed to violence and de-bunking patriarchal ideologies that encourage VAW using platforms such as the 
family, school, media, religious and other social group platforms for behavior change communication. Social media platforms, and phone-based applications/programs can also be used for behavior change communication particularly for the younger adults who have access to smart phones. Additionally, more intersectional collaboration between the education, health, and other sectors such as the entertainment industry towards combating VAW and the underlying determinants is highly encouraged. Some other solutions will include female education and empowerment, incentives and support for victims who report, unbiased prosecution and rehabilitation of perpetrators as well as welfare, rehabilitative and social assistance packages for victims and their families.

\section{Abbreviations}

AOR, adjusted odds ratio; CI, confidential interval; FGD, focus group discussions; VAPP, violence against persons prohibition; VAW, violence against women; GBV, genderbased violence; IPV, intimate partner violence.

\section{Data Sharing Statement}

The datasets used and/or analyzed during the current study are available from the corresponding author on reasonable request (ijeomaninadr@gmail.com).

\section{Acknowledgments}

The authors appreciate the technical support received from the African Institute for Health Policy and Health Systems, Ebonyi State University, Abakaliki, Nigeria.

\section{Author Contributions}

All authors made a significant contribution to the work reported, whether that is in the conception, study design, execution, acquisition of data, analysis and interpretation, or in all these areas; took part in drafting, revising or critically reviewing the article; gave final approval of the version to be published; have agreed on the journal to which the article has been submitted; and agree to be accountable for all aspects of the work.

\section{Funding}

This study was partly supported by the WHO-AFRO/ TDR/EDTCP small grants scheme for implementation research on infectious diseases of poverty and the African Institute for Health Policy and Health Systems, Ebonyi state University Abakaliki, Nigeria.

\section{Disclosure}

The authors declare that they do not have any conflicts of interest for this work.

\section{References}

1. World Health Organization. Violence against women. Fact Sheets; 2021. Available from: https://www.who.int/news-room/fact-sheets /detail/violence-against-women. Accessed December 1, 2021.

2. Pan American Health Organization. Understanding and addressing violence against women. Washington, D.C.; 2012. Available from: http://www.who.int/reproductivehealth/publications/violence/en/ index.html. Accessed December 1, 2021.

3. World Health Organization. Global and Regional Estimates of Violence Against Women: Prevalence and Health Effects of Intimate Partner Violence and Non-Partner Sexual Violence. World Health Organization; 2013:57.

4. United Nations Women. Gender-based violence in Nigeria during the Covid-19 crisis: the shadow pandemic; 2020:11-17. Available from: https://www.unwomen.org/en/news/. Accessed December 1, 2021.

5. United Nations. Declaration on the Elimination of Violence Against Women. New York: United Nations; 1993.

6. World Heath Organization, London School of Hygiene \& Tropical Medicine and SAMR, Council. Global and regional estimates of violence against women: prevalence and health effects of intimate partner violence and non-partner sexual violence; 2011: 29. Available from: https://www.who.int/reproductivehealth/publications/violence/ VAW_infographic.pdf?ua=1. Accessed December 1, 2021.

7. National Population Commission (NPC) and The DHS Program ICF. Nigeria Demographic and Health Survey 2018. Abuja, Nigeria and Rockville, Maryland, USA: National Population Commission (NPC), The DHS Program ICF; 2019.

8. Regional Office for Europe of the World Health Organization. The cycles of violence. The relationship between childhood maltreatment and the risk of later becoming a victim or perpetrator of violence; 2007. Available from: https://www.euro.who.int/_data/assets/pdf file/0008/98783/E90619.pdf?ua=1. Accessed December 1, 2021.

9. Chiu GR, Lutfey KE, Litman HJ, Link CL, Hall SA, McKinlay JB. Prevalence and overlap of childhood and adult physical, sexual, and emotional abuse: a descriptive analysis of results from the Boston area community health (BACH) survey. Violence Vict. 2013;28 (3):381-402. doi:10.1891/0886-6708.11-043

10. Fry DA, Elliott SP. Understanding the linkages between violence against women and violence against children. Lancet Glob Health. 2017;5(5):e472-3. doi:10.1016/S2214-109X(17)30153-5

11. Fakunmoju SB, Rasool S. Exposure to violence and beliefs about violence against women among adolescents in Nigeria and South Africa. SAGE Open. 2018;8(4):215824401881759. doi:10.1177/ 2158244018817591

12. Shields M, Tonmyr L, Hovdestad WE, Gonzalez A, MacMillan H. Exposure to family violence from childhood to adulthood. $B M C$ Public Health. 2020;20(1):1-15. doi:10.1186/s12889-020-09709-y

13. Till-Tentschert $U$. The relation between violence experienced in childhood and women's exposure to violence in later life: evidence from Europe. $J$ Interpers Violence. 2017;32(12):1874-1894. doi:10.1177/0886260517698952

14. Rosser-limiñana A, Suriá-martínez R, Pérez MÁM. Children exposed to intimate partner violence: association among battered mothers' parenting competences and children's behavior. Int J Environ Res Public Health. 2020;17(4):1134. doi:10.3390/ijerph17041134

15. United Nations Children's Fund (UNICEF). Behind closed doors: the impact of domestic violence on children [Internet]. Stop violence in the home campaign. New York; 2006. Available from: http://www.unicef.org/ protection/files/BehindClosedDoors.pdf. Accessed December 1, 2021. 
16. Kågesten A, Gibbs S, Blum RW, et al. Understanding factors that shape gender attitudes in early adolescence globally: a mixed-methods systematic review. PLoS One. 2016;11(6):e0157805. doi:10.1371/journal.pone.0157805

17. Sikweyiya Y, Addo-lartey AA, Alangea DO, Dako-gyeke P. Patriarchy and gender-inequitable attitudes as drivers of intimate partner violence against women in the central region of Ghana. BMC Public Health. 2020;20:682. doi:10.1186/s12889-020-08825-z

18. Ali TS, Karmaliani R, Mcfarlane J, et al. Attitude towards gender roles and violence against women and girls (VAWG): baseline findings from an RCT of 1752 youths in Pakistan. Glob Health Action. 2017;10(1). doi:10.1080/16549716.2017.1342454

19. Gage AJ, Thomas NJ. Women's work, gender roles, and intimate partner violence in Nigeria. Arch Sex Behav. 2017;46(7):1923-1938. doi:10.1007/s10508-017-1023-4

20. Ali TS, Krantz G, Gul R, Asad N, Johansson E, Mogren I. Gender roles and their influence on life prospects for women in urban Karachi, Pakistan: a qualitative study. Glob Health Action. 2011;4:7448. doi:10.3402/gha.v4i0.7448

21. Antai D. Controlling behavior, power relations within intimate relationships and intimate partner physical and sexual violence against women in Nigeria. BMC Public Health. 2011;11:511. doi:10.1186/ 1471-2458-11-511

22. Woldemicael G. Do women with higher autonomy seek more maternal health care? Evidence from Eritrea and Ethiopia: do women with higher autonomy seek more maternal health care? Evidence from Eritrea. Health Care Women Int. 2010;31(7):599-620. doi:10.1080/ 07399331003599555

23. Olayanju L, Naguib R, Amin S, et al. Gender- based violence in Nigeria: a cross-sectional study of the magnitude, likely risk factors and attitudes towards intimate partner violence against women. J Comput Innov Eng Appl. 2016;1(1):1-16.

24. Doku DT, Asante KO. Women's approval of domestic physical violence against wives: analysis of the Ghana demographic and health survey. BMC Women's Health. 2015;15:120. doi:10.1186/ s12905-015-0276-0
25. Law Padi. Laws against domestic violence in Nigeria. Available from: https://lawpadi.com/domestic-abuse-laws-in-nigeria/. Accessed December 1, 2021.

26. National Population Commission (NPC). Nigeria Demographic and Health Survey 2013. Abuja, Nigeria: ICF Macro; 2013.

27. USAID. Demographic and Health Survey's DHS Toolkit of methodology for the MEASURE DHS phase III project. 2013:1-51.

28. Johnson NA, Lavis JN. Procedures Manual for the "Evaluating Knowledge-Translation Platforms in Low- and Middle-Income Countries" Study. Hamilton: Canada Program in Policy Decision-Making; 2009.

29. IBM Corp. Released. IBM SPSS Statistics for Windows, Version 20.0. Armonk, NY: IBM Corp; 2011.

30. Umana JE, Fawole OI, Adeoye IA, et al. Prevalence and correlates of intimate partner violence towards female students of the University of Ibadan, Nigeria. BMC Women's Health. 2014;14(1):131. doi:10.1186/1472-6874-14-131

31. Kunnuji MON, Esiet A. Prevalence and correlates of sexual abuse among female out-of- school adolescents in Iwaya Community, Lagos State, Nigeria. Afr J Reprod Health. 2015;19(1):82-90.

32. Linos N, Slopen N, Subramanian SV, Berkman L, Kawachi I. Influence of community social norms on spousal violence: a population-based multilevel study of Nigerian women. Am J Public Health. 2013;103(1):148-155. doi:10.2105/AJPH.2012.300829

33. Mueller V, Jouriles EN, McDonald R, Rosenfield D. Adolescent beliefs about the acceptability of dating violence: does violent behavior change them? J Interpers Violence. 2013;28:436-450. doi: $10.1177 / 0886260512454716$

34. De Vries HD, Eggers SM, Jinabhai C, Meyer-Weitz A, Sathiparsad R, Taylor M. Adolescents' beliefs about forced sex in Kwazulu-natal, South Africa. Arch Sex Behav. 2014;43:1087-1095. doi:10.1007/ s10508-014-0280-8

35. Makama GA. Patriarchy and gender inequality in Nigeria: the way forward. Eur Sci J. 2013;9:115-144.

36. Chukuezi C. Socio-cultural factors associated with maternal mortality in Nigeria. Res J Soc Sci. 2010;1(5):22-26.
Risk Management and Healthcare Policy

\section{Publish your work in this journal}

Risk Management and Healthcare Policy is an international, peerreviewed, open access journal focusing on all aspects of public health, policy, and preventative measures to promote good health and improve morbidity and mortality in the population. The journal welcomes submitted papers covering original research, basic science, clinical \& epidemiological studies, reviews and evaluations, guidelines, expert opinion and commentary, case reports and extended reports. The manuscript management system is completely online and includes a very quick and fair peer-review system, which is all easy to use. Visit http://www.dovepress.com/testimonials.php to read real quotes from published authors. 